\title{
ÁREAS DE ADAPTAÇÃO À CULTURA DO MILHO, NA REGIÃO CENTRO DO BRASIL, A PARTIR DE ANÁLISES DE GRUPOS DE EXPERIMENTOS
}

\author{
LÚCIO BENEDICTO KROLL \\ Engo - Agro
}

Orientador: Prof. Dr. DÉCIO BARBIN

\begin{abstract}
Dissertação apresentada à Escola Superior de Agricultura "Luiz de Queiroz", da Universidade de São Paulo, para obtenção do título de Mestre em Agronomia, área de concentração em Estatística $\theta$ Experimentação Agronômica.
\end{abstract}

\author{
$P \mid R A C I C A B A$ \\ Estado de São Paulo - Brasil \\ Maio - 1983
}


ii.

Aos meus pais

e à minha esposa,

DEDTCO.

Aos meus filhos

$e$ aos meus irmãos,

OFEREÇO. 


\section{AGRADECIMENTOS}

Ao Professor Titular, Dr. Décio Barbin, pela orientação e estîmulo que ofereceu para a segura realização deste trabalho.

Ao Professor Titular, Dr. Humberto de Campos, Chefe do Departamento de Matemātica e Estatística da ESALQ/USP, pelo apoio e amiza de durante o Curso.

Aos Professores do Curso de Pós-Graduação em Estatĩstica e Experimentação Agronômica pela compreensão, ensinamentos e apoio.

Aos colegas do Curso pelo excelente convivio durante o mesmo.

Aos colegas do Departamento de Bioestatīstica da UNESP, Campus de Botucatu, pelo estīmulo, solidariedade e apoio.

A EMBRAPA, atravēs do CNMS, pela facilildade na obtenção dos dados.

Aos Professores Dr. Roland Vencovsky e Dr. Izaias Rangel Nogueira, pela orientação nos primeiros trabalhos.

Aos colegas Carlos Henrique Mattiolli e Valter João Dỉeh1, pelo auxỉlio prestado por ocasião da realízação dos cálculos.

A CAPES, pelo auxílio financeiro oferecido atravēs do PICD.

A todos os colegas que colaboraram comigo para a realização deste trabalho. 
Pág.

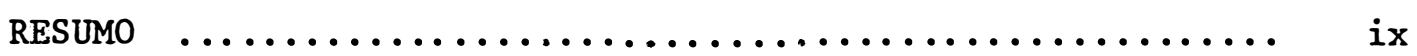

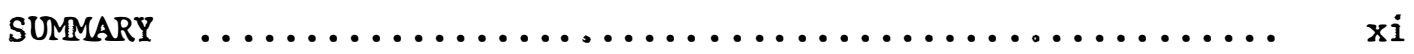

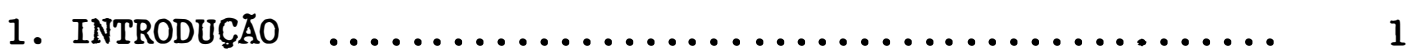

2. REVISÃo DE LITERATURA $\ldots \ldots \ldots \ldots \ldots \ldots \ldots \ldots \ldots \ldots \ldots \ldots \ldots \ldots \ldots \ldots \ldots$

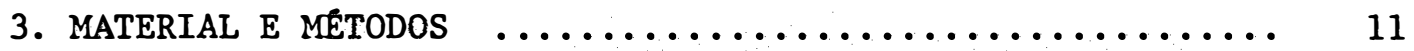

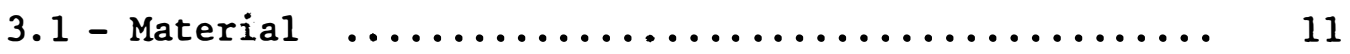

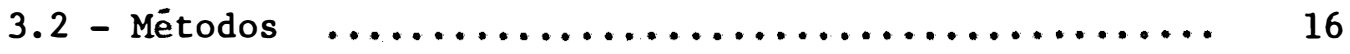

3.2.1 - Análise da variância conjunta dos dados para cada ano agricola $\ldots \ldots \ldots \ldots \ldots \ldots \ldots, 16$

3.2.2 - Anälise da variância conjunta dos pares de locais para cada ano agricola ......... 17

3.2.3 - Estimação dos componentes de variāncia $\left(\hat{\sigma}_{t \ell}\right)$ da interação cultivar por local ........ 19

4. RESULTADOS E DISCUSSĀo

4.1 - Anālise da Variância Conjunta dos Dados Para Cada Ano Agrícola .......................... 20

4.2 - Anālise da Variância Conjunta dos Pares de Locais.. 23

4.3 - Anālise da Variância Conjunta dos Dados de 36 Culti vares em Sete Locais, Considerando o Modelo Aleatörio

4.3.1 - Conjuntos de locais para o ano agricola 1976/

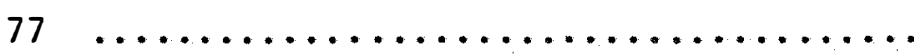

4.3.2 - Conjuntos de locais para o ano agricola 1977/ 78 
Päg.

4.3.3 - Conjuntos de loćais para o ano agricola 1978/ 79 ............................. 31

4.3.4 - Conjuntos de locais para o ano agricola 1979/

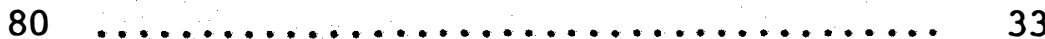

4.4 - Estimação dos Componentes de Variāncia $\left(\bar{\sigma}_{t \ell}\right)$ da Intẹ ração Cultivar por Local, para o Periodo de 1976 a 1980, Considerando os Grupos Formados Dentro de Cada Ano

5. CONCLUSỚES

6. BIBLIOGRAFIA

7. APENDICE 
1 Locais estudados nos experimentos do ENMN na região Centro, nos anos agrícolas 1976-77, 1977-78, 197879 e 1979-80

2 Esquema da análise da variāncia conjunta dos dados de I cultivares e J locais, considerando-se o mode1o aleatório

3.1 Anālise da variância conjunta para o ano agricola de 1976/77, relativa a 18 locais da Região Centro do Brasil, com 36 cultivares ..............

3.2 Anālise da variāncia conjunta para o ano agrícola de 1977/78, relativa a 17 locais da Região Centro do Brasil, com 36 cultivares .............

3.3 Anālise da variância conjunta para o ano agricola de 1978/79, relativa a 18 locais da Região Centro do Brasil, com 42 cultivares ..............

3.4 Anālise da variāncia conjunta para o ano agrícola de 1979/80, relativa a 17 locais da Região Centro do Brasil com 42 cultivares .............

4.1 - Valores da estatistica $F$ para os quadrados médios das interações $\mathrm{TxL}$, referentes aos pares de locais

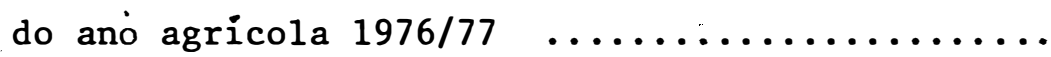


vii.

TABELA

Pảg.

4.2 Valores da estatistica $F$ para os quadrados médios das interações TxL, referentes aos pares de locais

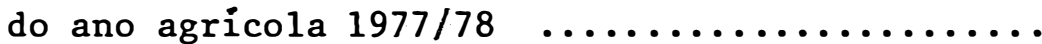

4.3 Valores da estatistica $F$ para os quadrados médios das interações TxL, referentes aos pares de locais

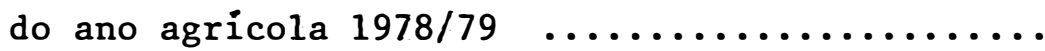

4.4 Valores da estatistica $F$ para os quadrados médios dàs interações TxL, referentes aos pares de locais

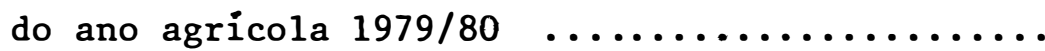

5.1.a Agrupamentos dos locais segundo a significāncia da interação cultivar por local para o ano agricola $1976 / 77$

5.1.b Agrupamentos dos locais segundo a significāncia da interação cultivar por local para o ano agricola $1976 / 77$

5.2. a Agrupamentos dos locais segundo a significância da interação cultivar por local para o ano agrícola $1977 / 78$

5.2.b Agrupamentos dos locais segundo a significância da interação cultivar por local para o ano agricola $1977 / 78$ 
viii.

TABELA

Pāg.

5.3.a Agrupamentos dos locais segundo a significância da interação cultivar por local para o ano agricola $1978 / 79$

5.3.b Agrupamentos dos locais segundo a significância da interação cultivar por local para o ano agricola

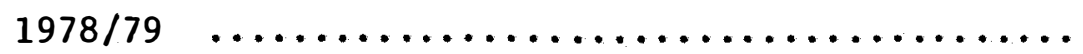

5.4.a Agrupamentos dos locais segundo a significância da interação cultivar por local para o ano agricola

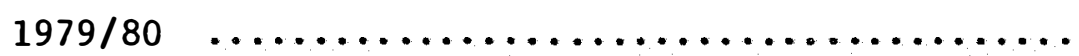

5.4.b Agrupamentos dos locais segundo a significância da interação cultivar por local para o ano agricola $1979 / 80$

- 6.1.a Anālise da variância conjunta das sete localidades do conjunto 5.1.a do ano agricola 1976/77 ......

6.1.b Anālise da variāncia conjunta das cinco localidades do conjunto 5.1.b do ano agricola 1976/77 ...

7.2. a Anālise da variāncia conjunta das sete localidades do conjunto 5.2.a do ano agricola 1977/78 ......

7.2.b Anālise da variância conjunta das três localidades do conjunto 5.2.b do ano agricola $1977 / 78$...... 
8.3.a Análise da variância conjunta das cinco localidades do conjunto 5.3.a do ano agrícola 1978/79 ...

8.3.b Anālise da variāncia conjunta das quatro localida des do conjunto 5.3.b do ano agricola 1978/79 ...

9.4.a Anālise da variância conjunta das sete localidades do conjunto 5.4.a do ano agricola 1979/80 ......

9.4.b Anālise da variância conjunta das seis localidades do conjunto 5.4.b do ano agricola $1979 / 80$......

10 Componentes de variância $\left(\bar{\sigma}_{t \ell}\right)$ da interação cultivar por local do periodo de 1976 a 1980 com os res pectivos intervalos de confiança, graus de liberda de associados e nümeros das tabelas de anälise ..

11 Quadrados médios residuais para os locais segundo o ano agricola ....................... 
AREAS DE ADAPTAÇAO A CULTURA DO MILHO, NA REGIÄO CENTRO DO BRASIL, A PARTIR DE ANALLISES DE GRUPOS DE EXPERIMENTOS

Autor: Lücio Benedicto Kroll

Orientador: Prof. Dr. Décio Barbin

Com o objetivo de obter agrupamentos homogêneos de 1ocais, através do estudo da magnitude da interação cultivar por 1ocal, foram analisadas as produções médias ajustadas de 111 cultiva res de milho provenientes de 42 municípios da região Centro (segundo Boletim Anual da EMBRAPA), compreendendo os Estados de Goiás, Mi nas Gerais, Mato Grosso do Sul, Paranā (Norte) e São Paulo, vincula dos ao programa do Ensaio Nacional de Milho Normal, desenvolvido sob a coordenação da Empresa Brasileira de Pesquisa Agropecuäria,du rante o período de 1976 a 1980.

Considerando-se que, quando as anâlises de variância apresentam efeitos significativos das interações cultivar por local, existe grande dificuldade na interpretação dos efeitos significati- 
vos de cultivares elou de locais, procedeu-se ao reagrupamento dos locais sob certos critérios, visando a diminuir o efeito significativo dessa interação.

No tocante à formação de grupos de locais/ano, esse crị tério basicamente consistiu na aplicação de anālise da variância con junta seguida de anālise da variância conjunta de pares de locais.

A anālise da variância dos conjuntos de locais assim ob tidos revelou uma redução média de cerca de $25 \%$ na magnitude das in teraçōes cultivar por local, quando as reuniões de conjunto de 1ocais foram processadas dentro de cada ano. 


\section{AREAS OF ADAPTATION TO CULTIVATION OF MAIZE BEGINNING BY ANALYSIS OF GROUP OF EXPERIMENTS, IN BRAZILIAN CENTER REGION}

Author: Lūcio Benedicto Kroll

Adviser: Prof. Dr. Décio Barbin

\section{$S U M M A R Y$}

The aim of this paper is to obtain homogeneous sets of locals, through the magnitude of interaction cultivar versus local. It was analised adjusted averages of yields of 111 cultivars proceeding from 42 .contries of the States of Goiảs, Minas Gerais, Mato Grosso do Sul, Paranả and São Paulo, linked to the program of "Ensaio Nacional do Milho Normal", under the co-ordenation of the "EMBRAPA", from 1976 through 1980.

When the analysis of variance presents significants effects of the interactions cultivar versus local, there is great difficulty to interpret the significative effects of the cultivars and/ or of locals then it was proceeded the rearrange of locals, under determined criterions, intending to atenuate the significant effect of this interaction. 
xiii.

Relating to the formation of sets of locals/years those criterions constituted of conjunct analyses continued by analyses of the couples of locals.

The analysis of the groups thus obtained showed a mean reduction about $25 \%$, in the magnitude of the interaction cultivars versus local, when the groups were made into each year. 
1. INTRODUÇAOO

0 milho (Zea mays L.) è um cereal de grande importân cia como fonte de proteínas, cultivado em quase todas as regiões agrícolas do mundo. Existem, por isso, cultivares (populações, varie dades, linhagens, etc.) adaptadas a todos os ambientes.

A adaptação de uma dada cultivar influi no total de sua produção, justificando, portanto, o uso de testes com vistas ao estudo da sua produção em diferentes anos e locais.

Assim, dentro de uma região produtora de milho, a prática usualmente seguida consiste em analisar o rendimento médio de cada cultivar, sem levar em conta diversos fatores (solo, clima, etc.), a fim de recomendar as 'cultivares que apresentam maior produtividade. Contudo, o uso de valores médios de produção de milho, ao invés de valores individuais, pode ocasionar a perda de informa- 
mações referentes às regiões cujos ambientes não permitem a manuten ção do mesmo comportamento das cultivares.

0 teste da interação cultivar por local, quase sempre significativo (RUSCHEL, 1968), permite detectar a influencia do local sobre as produções das cultivares.

Esse procedimento empírico (uso de médias de produção) apresenta falhas que somente serão eliminadas quando em seu lu gar utilizarmos métodos científicos para recomendar melhores cultivares às diferentes regiões.

Entre os métodos propostos, com essa finalidade, des taca-se o da regionalização, que se baseia no reagrupamento de 1ocais, visando diminuir o efeito da interação cultivar por local.

'Quando nas anālises de variância resultam efeitos sig nificativos das interações cultivar por local, entende-se que não hâ um comportamento análogo das cultivares no conjunto de loćais. Isto impede uma interpretação mais ampla de um possível efeito significativo de cultivar e/ou de local, o que dificulta a indicação das melhores cultivares e, em consequência, a execução de planos de melhoramentos.

Assim, o presente estudo tem por objetivo apresentar critério de reagrupamento ou formação de conjuntos de locais que se jam tão homogêneos quanta possível e apresentem sensíveis reduções nos quadrados médios das interações cultivar por local. 


\section{REVISAO DE LITERATURA}

Na presente revisão de literatura, nos preocupamos apenas com trabalhos relacionados com a obtenção de conjunto de locais, com a finalidade de conseguirmos o ajustamento das necessidades da cultura do milho às condições ambientais.

Essa revisão seguiu uma ordem lógica para o desenvol vimento do presente trabalho.

ALLARD e BRADSHAW (1964) afirmam ser muito vasta a literatura sobre a interação genótipo por ambiente (GA), salientando a dificuldade de uma revissão completa sobre o assunto. Por outro lado, classificam as variações ambientais em previsíveis (ti po de solo, tratos culturais, época de plantio, etc.) e não previsíveis (os regimes de chuvas, temperaturas, etc.), sugerindo os respectivos controles. Para as variações não previsíveis o controle se obtém mediante o emprego de cultivares adaptadas âs flutuações am bientais. Os autores salientam que as variações relacionadas com a in 
teração significativa cultivar por ano são devidas a fatores ambien tais não previsíveis.

HORNER e FREY (1957) conseguiram uma redução de 30\% na interação variedade por local mediante uma subdivisão do Estado de Iowa em classes de $2,3,4$ e 5 regiões. A cada uma dessas subdivisões correspondiam distintos agrupamentos de locais,para experimentos realizados em 9 locais durante um período de 5 anos. Apenas 5 variedades eram comuns a todos os anos. A redução do quadrado médio foi avaliada em relação ao quadrado médio do Estado de Iowa (USA), para cada agrupamento de local em cada uma das quatro regionalizações. Os resultados do teste de Tippet, comparando para cada classe de subdivisão o agrupamento com mêdia mais baixa de quadrados mëdios, relativos ao período estudado, com o do Estado como um todo, são apresentados numa tabela de acordo com on diferente número de sub-regiões.

MCCAIN e SCHULTZ JR. (1959) efetuaram um estudo utilizando dados de produção de milho de 15 locais para um período de 6 anos, no Estado de Alabama, USA, aplicando testes para variedades. Os locais foram agrupados dois a dois em todas as possiveis combina ções. Os quadrados médios para a interação variedade por local foram calculados para cada par de locais em cada ano. Os 630 quadrados médios foram tabulados, e calculadas as 105 médias de quadrados médios para os pares de locais envolvidos. Essas médias também foram dispostas numa tabela triangular. A anālise feita com esses qua 
drados médios permitiu indicar duas āreas relativamente homogêneas (Norte e Sul) e uma ārea heterogênea (Central). Os autores sugeriram também testes de locais nesta região central com a finalidade de delinear sub-regiões de adaptação.

RUSCHEL (1968), estudando a produção de milho no Cen tro Sul do Brasil, realça o fato de haver encontrado interação alta mente significativa do genótipo por local, aconselhando a escolha das melhores populações de cultivares para cada região, a fim de que se possam efetuar trabalhos de melhoramentos.

SILVA e MAGNAVACA (1970), utilizando seis locais do Ensaio Nacional do Milho, em 1968/69, na ärea do IPEACO, efetuaram anảlises de variância de todos os pares possíveis de locais, segundo o modelo indicado por Kempthorne (1952) para média de três pares de locais com considerāvel redução das componentes da interação variedade por local.

SILVA et alii (1963) analisaram os resultados de um ensaio de produção de milho com cinco a seis repetições, em diferen tes localidades do Estado de São Paulo, nos anos de 1945 a 1953. Os locais abrangiam äreas representativas dos diferentes tipos de solo e clima. Esse trabalho permitiu constatar que o efeito de localidades sobre a variabilidade de produção das cultivares foi o mais importante, seguido dos efeitos de anos e das repetições. Concluiram, ainda, que o efeito do solo è mais importante que o efeito do clima de ano para ano. 
Un método de anālise conjunta de experimentos instalados em diversos locais durante dois anos, em que apenas parte dos tratamentos e locais é comum a todos os anos, foi desenvolvido por IGNAZAK e SILVA (1978). Esse trabalho estudou uma situação que frequentemente $\bar{e}$ comum em programas de melhoramentos.

LIANG et alii (1966), estudando as interações variedade por local, consideraram ensaios de cultivares de trigo, cevada e aveia, realizados durante três anos, no Estado de Kansas. Foram avaliadas dez variedades de trigo em treze localidades, quatro variedades de cevada em dez localidades e cinco variedades de aveia em cinco localidades. Os autores constataram que as interações varieda de por ano foram não significativas, mas as interações variedades por local por ano foram altamente significativas. A interação tripla deve ser considerada como um resíduo a seŕ controlado pelo núme ro de localidades usadas e o nümero de anos do teste. As interações variedade por local, que foram significativas para o trigo e a ceva da, serviram para indicar que aquele Estado deveria ser dividido em sub-āreas de cultivo, para cada uma dessas espécies. Mediante um agrupamento apropriado de locais, os autores conseguiram reduzir os quadrados médios das interações variedade por local, sugerindo, con tudo, que cada sub-ārea deveria ser considerada como uma unidade in dependente, ao testar a significância destas interações.

SCHLEHUBER et-alii (1970) estudaram cultivares de tri go no Rio Grande do Sul, trabalhando com trinta cultivares em sete 
locais no ano agrícola de $1966 / 67$, e com vinte cultivares semeados em oito locais no ano agrícola de 1967/68, sendo que apenas dezoito variedades foram comuns em ambos os anos. A média da produção de grãos (em kg/ha), de cada cultivar por local, foi correlacionada com a média de produção de todos os outros locais. Apesar do pequeno nú mero de correlações significativas entre locais, certas cultivares apresentaram-se de modo superior em muitos locais, indiferentemente do valor dos coeficientes de correlações entre estes locais. Dessa forma, os coeficientes de correlações encontrados, meramente ilustram interrelações gerais.

Um estudo estatístico teórico sobre o coeficiente de correlação genética foi realizado por ROBERTSON (1959), que estabeleceu uma fórmula permitindo calcular o efeito devido às diferenças na variação entre genōtipos, em ambientes diferentes, bem como o efeito rèlativo à falta de correlação entre os genōtipos nesses ambientes distintos.

MOREIRA et alii (1971), complementando o trabalho de SCHLEHUBER et alii (1970), incluiram o ano agrícola de 1968, comvin te e cinco variedades em oito locais. Os rendimentos obtidos em 1966 e 1968 foram consideravelmente maiores do que os de 1967. Dos coefí cientes de correlações possíveis entre locais, apenas 25 foram esta tisticamente significativos e, destes, apenas três foram negativos. As conclusões foram anālogas às do trabalho anterior. 
OSÓRIO et alii (1974) estudaram o comportamento de quinze cultivares de trigo precoce, no Rio Grande do Sul, através das produções médias comparadas em cada região tritícola. o delinea mento utilizado foi o de blocos ao acaso, com quatro repetições,ten do sido utilizado o teste sugerido por COCHRAN e COX (1957), de homogeneidade de variâncias, a fim de comparar as cultivares por suas médias gerais no Estado. Os autores concluiram que as cultivares que na média geral do Estado se destacaram como as mais produtivas tive ram também comportamento superior em cada região, com poucas exceções.

ROSITO (1974), no Rio Grande do Sul, procurou avaliar a interação cultivar por local para as äreas tritícolas do Estado, a fim de verificar se a regionalização existente era adequada. 0 autor verificou a existência de interação significativa genótipo por local, mesmo tratando-se de cultivares jā selecionados pela média de produção do Estado. Constatou ainda que a característica do tratamento permaneceu sensível às mudanças locais. Alēm destas conclusões, o trabalho apresenta outras, destacando-se a referente ao razoável grau de compatibilidade entre a regionalização tritícola existente no Estado e a interação de genötipos por locais.

EBERHART e RUSSEL (1966) usaram um modelo que define parâmetros de estabilidade, que podem ser usados para descrever o desempenho de uma variedade sobre uma série de ambientes. o coefi ciente de regressão e a soma dos quadrados dos desvios da regressão 
são utilizados como medidas de estabilidade.

JOWETT (1972) realizou um estudo que permitiu uma avaliação comparativa de parâmetros de estabilidade fenotípica de plantas, usando dados originados de experimentos com sorgo.

Vários autores têm utilizado processos multivariados como, por exemplo, o método da conglomeração para a regionalização de āreas de plantio de cultivares agrícolas, destacando-se os traba Thos de ABOU-EL-FITTOUH et alii (1969), CAMPBELL e LAFEVER (1977), CORDEEIRO (1968).

Um amplo trabalho de revisão descrevendo os vārios métodos estatísticos para analisar interações de modo geral, e inte rações genótico ambiente em particular, com muitas referências bibliogrāficas, foi elaborado por FREEMAN (1973).

SILVA (1981) aplicou diferentes métodos a fim de verificar se a regionalização existente no Estado do rio Grancie do SuI para a cultura do trigo era adequada, e além disso objetivou oferecer subsídios ao seu aprimoramento.

SILVEIRA (1980), com dados de três séries de ensaios realizados no período agrícola de 1974-77, estudou a interação genó tipo por local e a sub-regionalização da região de arroz de sequeiro no Estado de São Paulo. Com essa finalidade, foram feitas anālises simples e conjunta da variância, na identificação das interações cultivares por locais e na avaliação de suas componentes na va riabilidade total. Este autor utilizou a anālise de variância pro- 
posta por EBERHART e RUSSEL (1966) no estudo da estabilidade fénoti pica.

$$
\text { CORDEIRO (1978), utilizando os resultados do Ensaio }
$$
Nacional do Milho referente aos anos $1974-77$ e tomando como variävel o peso de espigas despalhadas, fez um estudo que permitiu uma apreciação critica do atual zoneamento da região Centro-Sul do Brasil, para a cultura do milho. A base estatistica consistiu na anäli se das interações cultivar por local. 
11.

3. MATERIAL E METODOS

\section{1 - Material}

Os dados utilizados no presente trabalho são provenientes do Ensaio Nacional de Milho Normal (ENMN), nos anos agrícolas $1976-77$, 1977-78, 1978-79 e 1979-80, coordenados pelo Centro Na cional de Pesquisa de Milho e Sorgo (CNPMS), situado em Sete Lagoas, Estado de Minas Gerais, pertencente ả Empresa Brasileira de Pesquisa Agropecuária (EMBRAPA). o referido ensaio foi executado no perío do acima, na região Centro, compreendendo localidades pertencentes aos Estados de São Paulo, Minas Gerais, Goiās, Mato Grosso do Sul, Distrito Federal e norte do Paranā, pelas seguintes instituições:

- Agroceres S/A, Importação, Exportação e Comércio;

- Fundação Cargill; 
- Instituto Agronômico do Paranā (IAPAR);

- Escola Superior de Agricultura "Luiz de Queiroz";

- Instituto Agronômico de Campinas;

- Faculdade de Agronomia de Jaboticabal;

- Plantec - Agropecuāria, Planejamento e Assistência Agropecuā ria Ltda.;

- Contibrasil;

- Universidade Federal de Viçosa;

- Empresa de Pesquisa Agropecuāria de Minas Gerais (EPAMIG);

- Centro de Pesquisa Agropecuāria dos Cerrados (CPAC);

- Empresa Goiana de Pesquisa Agropecuāria (E GOPA);

- Dekalb Agrícola do Brasil Ltda.;

- Sementes Reis de Ouro;

- Instituto Biológico de São Paulo - Fazenda Mato Dentro;

- UEPAE de Dourados;

- Cooperativa de Cotia de São Gotardo;

- Mogiana (Sementes);

- Pioneer Agricultura Ltda.;

- Dinamilho - Produtos Agrícolas Ltda.;

- CEPET;

- Universidade de Campinas;

- Escola Superior de Agricultura de Lavras;

- Sociedade Agrícola Germinal Ltda.;

- Sementes União Ltda. 
0 delineamento experimental utilizado pelo CNPMS nos anos agrícolas 1976-77 e 1977-78 foi o reticulado quadrado ("1attice square") $6 \times 6$, simples, duplicado, fornecendo 4 repetições para cada tratamento. Para os demais anos agrícolas estudados no presente trabalho, o delineamento experimental utilizado foi o reticulado retangular ("rectangular lattice") 6x7, simples duplicado, com um total de 4 repetições para cada tratamento.

Outras informações técnicas sobre o ensaio, bem como relativas aos dados, encontram-se nos boletins da EMBRAPA (1976 a 1980)

A distribuição geogrāfica das localidades onde foram realizados os experimentos do ENMN na região Centro, e que constituiram objeto deste estudo, encontra-se na Figura 1.

As localidades onde foram instalados os ensaios e abrangidos por este estudo, foram em número de 28 e estão relacionadas na Tabela 1 .

As cultivares ensaiadas no decorrer dos quatro anos agrícolas mencionados foram em nümero de 111 , das quais 81 foram cul tivadas em apenas um dos anos, 20 em dois, 6 em três e somente 4 em todos os anos.

Para a anālise estatística foram utilizadadas as pro duções mëdias ajustadas de espigas despalhadas em quilogramas por hectare. 


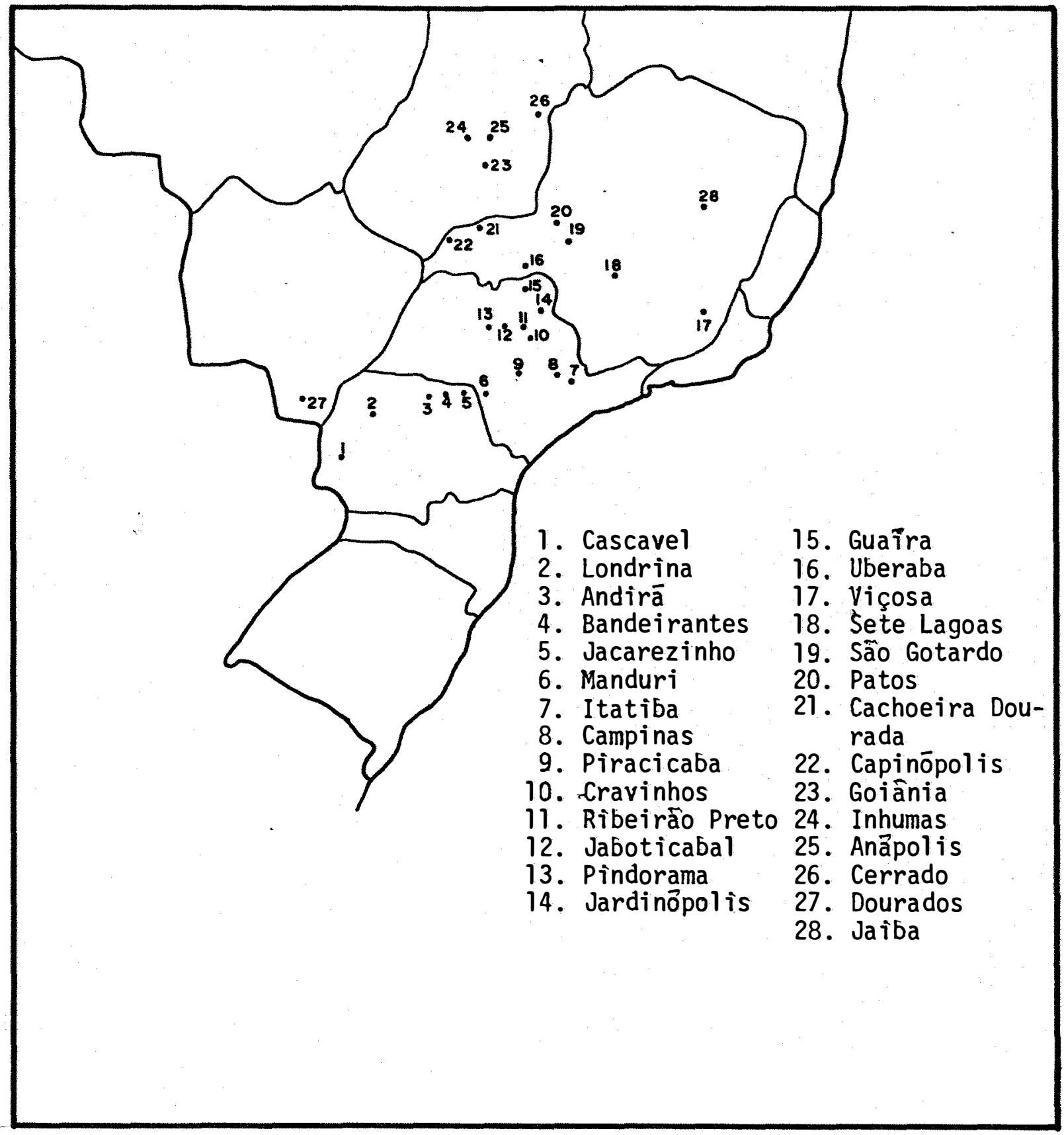

Figura 1 - Localidades da regiâo Centro do Brasil onde foram realizados os experimentos do ENMN, e cujos dados foram utilizados para estudo (anos agrícolas de 1976-77, 1977-78, 1978-79 e 1979-80). 
Tabela 1 - Locais estudados nos experimentos do ENMN na região Centro, nos anos agrícolas 1976-77, 1977-78, 1978-79, 1979-80 .

\begin{tabular}{|c|c|c|c|c|c|c|}
\hline \multirow{2}{*}{ NQ } & \multirow{2}{*}{ LOCAL } & \multirow{2}{*}{ ESTADO } & \multicolumn{4}{|c|}{ ANOS AGRICOLAS } \\
\hline & & & $1976-77$ & $1977-78$ & $1978-79$ & $1979-80$ \\
\hline 1 & Cascave 1 & PR & $\mathrm{X}$ & $\mathrm{X}$ & & \\
\hline 2 & Londrina & PR & $\mathrm{X}$ & $\mathrm{X}$ & $\mathrm{X}$ & $\mathrm{X}$ \\
\hline 3 & Andirā & PR & $\mathrm{X}$ & $\mathrm{X}$ & $\mathrm{X}$ & \\
\hline 4 & Bandeirantes & PR & & & $\mathrm{X}$ & $\mathrm{x}$ \\
\hline 5 & Jacarezinho & PR & $\mathrm{x}$. & & $\mathrm{X}$ & $\mathrm{X}$ \\
\hline 6 & Manduri & SP & $\mathrm{X}$ & & $\mathrm{X}$ & $\mathrm{X}$ \\
\hline 7 & Itatiba & SP & & $\mathrm{X}$ & $\mathrm{X}$ & $\mathrm{X}$ \\
\hline 8 & Campinas & SP & $\mathrm{X}$ & $\mathrm{X}$ & $\mathrm{X}$ & $\mathrm{X}$ \\
\hline 9 & Piracicaba & SP & $\mathrm{X}$ & & & $\mathrm{X}$ \\
\hline 10 & Cravinhos & SP & $\mathrm{X}$ & $\mathrm{X}$ & $\mathrm{X}$ & $\mathrm{X}$ \\
\hline 11 & Ribeirão Preto & SP & $\mathrm{X}$ & & $\mathrm{X}$ & $\mathrm{X}$ \\
\hline 12 . & Jaboticabal & SP & $\mathrm{X}$ & $\mathrm{X}$ & & $\mathrm{X}$ \\
\hline 13 & Pindorama & SP & $\mathrm{X}$ & $\mathrm{X}$ & $\mathrm{X}$ & \\
\hline 14 & Jardinōpolis & SP & $\mathrm{X}$ & & $\mathrm{X}$ & $\mathrm{X}$ \\
\hline 15 & Guaira & SP & $\mathrm{X}$ & $\mathrm{X}$ & $\mathrm{X}$ & $\mathrm{X}$ \\
\hline 16 & Uberaba & MG & $\mathrm{X}$ & $\mathrm{X}$ & $\mathrm{X}$ & $\mathrm{X}$ \\
\hline 17 & viçosa & MG & $\mathrm{X}$ & $\mathrm{X}$ & $\mathrm{X}$ & $\mathrm{X}$ \\
\hline 18 & Sete Lagoas & MG & $\mathrm{X}$ & $\mathrm{X}$ & $\mathrm{X}$ & $\mathrm{X}$ \\
\hline 19 & São Gotardo & MG & & & $\mathrm{X}$ & $\mathrm{X}$ \\
\hline 20 & Patos & MG & $\mathrm{X}$ & $\mathrm{X}$ & $\mathrm{X}$ & \\
\hline 21 & Cachoeira Dourada & MG & $\mathrm{X}$ & & $\mathrm{X}$ & \\
\hline 22 & Capinōpolis & MG & & $\mathrm{X}$ & $\mathrm{X}$ & $\mathrm{X}$ \\
\hline 23 & Goiânia & GO & $\mathrm{X}$ & $\mathrm{X}$ & $\mathrm{x}$ & $\mathrm{X}$ \\
\hline 24 & Inhumas & GO & $\mathrm{X}$ & $\mathrm{X}$ & & $\mathrm{X}$ \\
\hline 25 & Anāpolis & GO & & $\mathrm{X}$ & $\mathrm{x}$ & \\
\hline 26 & Cerrado & $\mathrm{DF}$ & $\mathrm{X}$ & $\mathrm{X}$ & & $\mathrm{X}$ \\
\hline 27 & Dourados & MS & & & $\mathrm{X}$ & $\mathrm{X}$ \\
\hline 28 & Jaiba & MG & $\mathrm{X}$ & $\mathrm{X}$ & $\mathrm{X}$ & $\mathrm{X}$ \\
\hline
\end{tabular}


Os cálculos utilizados nas anālises de variância des te trabalho foram feitos no computador IBM 1130 da ESALQ/USP, Piracicaba, SP.

\section{2 - Métodos}

\subsection{1 - Anālise da variância conjunta dos dados para cada ano agricola}

Inicialmente foram realizadas anālises da variância conjunta para cada ano agrícola, com a finalidade de se estimarem e se testarem as interações cultivar por local, de acordo com a metodologia descrita por PIMENTEL GOMES (1976).

Para estas anālises foram calculadas as estimativas dos quadrados médios residuais (QMR) de cada local dentro de um mes mo ano, com o auxílio dos coeficientes de variação fornecidos pelos Boletins Anuais da EMBRAPA, publicados juntamente com as médias ajustadas de produção referentes às anālises dos "square lattice" do Ensaio Nacional do Milho Normal.

Com os QMR de cada local dentro de ano, obtiveram-se os valores dos quadrados mëdios residuais combinados ( $Q M R_{c}$ ). Esses QMR $_{c}$ serviram de resíduos para as anālises de variância conjunta con forme o esquema da Tabela 2 . 
Tabela 2 - Esquema da anälise da variāncia conjunta dos dados de I cultivares e J locais, considerando-se o modelo aleatório.

\begin{tabular}{lcc}
\hline Causas da Variação & G.L. & E(QM) \\
\hline Local (L) & $\mathrm{J}-1$ & \\
Cultivar (T) & $\mathrm{I}-1$ & \\
Interação (TxL) & $(\mathrm{J}-1)(\mathrm{I}-1)$ & $\sigma^{2} / \mathrm{r}+\mathrm{ro}_{\mathrm{tl}}^{2}$ \\
\hline Residuo Médio Combinado & $\mathrm{J}(\mathrm{r}-1)(\mathrm{I}-1)$ & $\sigma^{2} / \mathrm{r}$ \\
\hline
\end{tabular}

onde, $\sigma^{2}=$ esperança matemática do quadrado médio residual; $\sigma_{t \ell}^{2}=\begin{aligned} & \text { esperança matemática da componente de variāncia da inte- } \\ & \text { raça TxL; }\end{aligned}$

$\mathrm{J}=$ nümero de locais;

$I=$ nümero de cultivares;

$\mathrm{r}=$ nümero de repetições por cultivar no ensaio original.

Para efetuar essas análises foi verificado, previamente, a relação entre o maior e o menor quadrado médio residual, a fim de assegurar a homogeneidade entre eles, de acordo com Box(1954) citado em PIMENTEL GOMES (1976).

\subsection{2 - Anālise da variância conjunta dos pares de locais para cada ano agrïcola}

Os locais correspondentes a cada ano agrícola foram agrupados dois a dois, e para cada par fez-se uma análise da variân cia conjunta, segundo o esquema da Tabela 2 (com J=2). Essas anâlises objetivaram isolar os efeitos das interações QM(TxL) para o par analisado, e conseguir agrupamentos em conjuntos de locais ecologi- 
camente semelhantes.

0 critério para formação de grupos de locais baseou-se nos valores da estatística F obtidos por meio da relação:

$$
F=\frac{Q M(T x L)}{Q M R_{c}},
$$

onde,

$$
\begin{aligned}
\mathrm{QM}(\mathrm{TxL})= & \text { quadrado mëdio da interação cultivar por local para } \\
& \text { o par analisado; } \\
\mathrm{QMR}_{\mathrm{C}=} & \text { a média aritmética ponderada pelos respectivos graus } \\
& \text { de liberdade dos QMR dos locais envolvidos na anäli } \\
& \text { se. }
\end{aligned}
$$

Os conjuntos de locais são as reuniões dos mesmos com base nos valores da estatistica $F$ da interação (TxL) não significativa, ou próximos dos limites da não significằncia, aos niveis usuais de probabilidade $(\alpha=0,05 ; \alpha=0,01$ e $\alpha=0,001)$.

Obtidos os conjuntos supostos ecologicamente semelhan tes, fizeram-se novas análises de variância conjunta, respeitando-se o critērio de homogeneidade de variância, segundo o esquema da Tabe1a 2, item 3.2.1. 
3.2.3 - Estimação d s componentés de variāncia $\left(\hat{\sigma}_{t \ell}^{2}\right)$ da in teração cultivar por local

Conhecidos os $\mathrm{QM}(\mathrm{TxL})$ e os $\mathrm{QMR}_{\mathrm{c}}$ atravēs das anālises de variância, de acordo com o esquema da Tabela 2, foram estimadas as componentes de variância da interação $\widehat{\sigma}_{t \ell}^{2}$ e construídos os inter valos de confiança com 0,95 de probabilidade.

Os intervalos de confiança para $\sigma_{t_{\ell}}^{2}$ foram obtidos mediante a aplicação da distribuição $\chi^{2}$ (qui-quadrado) ou $t$ de Student, computando-se o nümero de graus de liberdade para essas estatísticas mediante o emprego da förmula de SATTERTHWAITE (1946). A distr $\underline{i}$ buição $t$ foi utilizada sempre que o nümero de graus de 1iberdade cal culado para $\hat{\sigma}_{\text {tl }}^{2}$ ultrapassava 30 .

As fỏrmulas para o cálculo dos intervalos de confian ça foram as seguintes:

$$
\hat{\sigma}_{t \ell}^{2} \pm t \sqrt{\frac{2\left(\hat{\sigma}_{t \ell}^{2}\right)^{2}}{f+2}}
$$

ou,

$$
\frac{f \hat{\sigma}_{t \ell}^{2}}{x_{\text {sup. }}^{2}} \leq \sigma_{t \ell}^{2} \leq \frac{f-\hat{\sigma}_{t \ell}^{2}}{x_{\text {inf }}^{2} .}
$$

conforme o valor de $\mathrm{f}$, que é o nümero de graus de liberdade associa do à estimativa da variância da interação cultivar por local. 
4. RESULTADOS E DISCUSSÃO

4.1 - Anālise da variância conjunta dos dados para cada ano agrĩ cola

Os resultados das anālises da variância conjunta dos dados para cada ano agrícola, do período $1976^{\circ}$ a 1980 , encontram-se nas Tabelas $3.1,3.2,3.3$ e 3.4 , respectivamente.

Tabela 3.1 - Análise da variância conjunta para o ano agrícola 1976/ 77, relativa a 18 locais da Região Centro do Brasil,com 36 cultivares.

\begin{tabular}{lrrrr}
\hline Causas da Variação & G.L. & S.Q. & Q.M. & F \\
\hline Local (L) & 17 & $1.471 .434 .449,00$ & & \\
Cultivar (T) & 35 & $73.348 .752,00$ & & \\
Interação (TxL) & 595 & $232.891 .600,10$ & $391.414,45$ & $2,45 *$ \\
\hline Res. Médio Comb. & 1.890 & & $159.643,58$ & \\
\hline
\end{tabular}

Média $=5.172,60 \mathrm{~kg}$

C.V. $=12,09 \%$ 
Tabela 3.2 - Anālise da variância conjunta para o ano agrícola 1977/ 78, relativa a 17 locais da Região Centro do Brasil com 36 cultivares.

\begin{tabular}{lrrrr}
\hline Causas da Variação & G.L. & S.Q. & Q.M. & F \\
\hline Local (L) & 16 & $2.514 .718 .611,00$ & & \\
Cultivar (T) & 35 & $173.979 .200,10$ & & \\
Interação (TxL) & 560 & $345.900 .240,20$ & $617.679,00$ & $2,77 *$ \\
\hline Res. Médio Comb. & 1.785 & & $222.661,64$ & \\
\hline
\end{tabular}

Média $=5.403,30 \mathrm{~kg}$

C.V. $=14,54 \%$

Tabela 3.3 - Anālise da variância conjunta para o ano agrî́cola 1978/ 79, relativa a 18 locais da Região Centro do Brasil com 42 cultivares.

\begin{tabular}{lrrrr}
\hline Causas da Variação & G.L. & S.Q. & Q.M. & F \\
\hline Loca1 (L) & 17 & $2.301 .801 .315,00$ & \\
Cultivar (T) & 41 & $395.510 .272,20$ & & \\
Interação (TxL) & 697 & $405.501 .568,30$ & $581.781,30$ & 2,01 * \\
\hline Res. Médio Comb. & 2.214 & & $288.720,44$ & \\
\hline
\end{tabular}

Média $=6.944,10 \mathrm{~kg}$

$\mathrm{C} . \mathrm{V} .=10,98 \%$ 
Tabela 3.4 - Anālise da variância conjunta para o ano agrỉcola 1979/ 80 , relativa a 17 locais da Região Centro do Brasil com 42 cultivares.

\begin{tabular}{lrrcc}
\hline Causas da Variação & G.L. & S.Q. & Q.M. & F \\
\hline Local (L) & 16 & $1.388 .077 .281,00$ & & \\
Cultivar (T) & 41 & $542.029 .264,70$ & & \\
Interação (TxL) & 656 & $459.056 .192,20$ & $699.780,78$ & $2,36 *$ \\
\hline Res. Médio Comb. & 2.091 & & $296.044,96$ & \\
\hline
\end{tabular}

Média $=6.614,3 \mathrm{~kg}$

C.v. $=12,64 \%$

Observa-se, através das análises conjuntas, que os coeficientes de variação se mantém entre $10,98 \%$ e $14,54 \%$, valores estes que são plenamente adequados, segundo o critério preconizado por SNEDECOR (1967), que estabelece os limites de $5 \%$ e $15 \%$ como satisfatórios para ensaios com milho.

As interações cultivar por local nessas anâlises,quan do verificados os valores da estatística $F$, foram todas significat vas para todos os anos agrícolas.

Os quadrados médios residuais para os locais de cada ano agrícola, que permitem o cálculo dos QMR $_{c}$ utilizados como denominador para obtenção dos valores da estatística $F$ encontram-se na Tabela 11 do Apêndice.

Os resultados significativos encontrados utilizando a estatística $\mathrm{F}$ indicam diferenças no comportamento das cultivares 
nos locais em cada ano agrícola, e são concordantes com aqueles obtidos por RUSCHEL (1968) em anālises com cultivares de milho na região Centro-Sul do Brasil.

\section{2 - Anālise da Variāncia Conjunta dos Pares de Locais}

A magnitude da interação cultivar por local, relacio nada com o Resíduo Médio Combinado para as 578 anālises de variância conjunta de pares de locais, revelou um critério útil para a formação de conjuntos de locais, permitindo, dessa maneira, a subdi visão da ārea total estudada, em conjunto de locais homogêneos dentro de cada ano.

Os valores da estatística $\mathrm{F}$, referentes a cada par de locais, são apresentados nas Tabelas $4.1,4.2,4.3$ e 4.4 do Apêndice, de acordo com o respectivo ano agrícola.

Com os valores de $\mathrm{F}$ assim obtidos, e utilizando-se os níveis usuais de significância, conseguiu-se a separação de conjuntos de locais homogêneos, descritos nas seguintes tabelas:

- Ano agrícola 1976/77, Tabelas 5.1.a e 5.1.b;

- Ano agrícola 1977/78, Tabelas 5.2.a e 5.2.b;

- Ano agrícola 1978/79, Tabelas 5.3.a e 5.3.b;

- Ano agrícola 1979/80, Tabelas 5.4.a e 5.4.b. 
Tabela 5.1.a - Agrupamentos dos locais segundo a significância da in teração cultivar por local para o ano agrícola 1976/ 77.

\begin{tabular}{|c|c|c|c|c|c|c|}
\hline & Guaira & Manduri & $\begin{array}{l}\text { Pindo- } \\
\text { rama }\end{array}$ & $\begin{array}{l}\text { Jardinó- } \\
\text { polis }\end{array}$ & $\begin{array}{c}\text { Sete } \\
\text { Lagoas }\end{array}$ & Jaiba \\
\hline Campinas & ns & ns & ns & ns & ns & $\star \star$ \\
\hline Guaira & - & ns & ns & * & ns & $\star \star$ \\
\hline Manduri & & - & ns & ns & ns & $\star \star$ \\
\hline Pindorama & ' & & - & $\star \star$ & * & ns \\
\hline Jardinōpolis & & & & - & ns & $\star \star$ \\
\hline Sete Lagoas & & & & & - & ns \\
\hline
\end{tabular}

Tabela 5.1.b - Agrupamentos dos locais segundo a significância da in teração cultivar por local para o ano agrícola 1976/ 77 .

\begin{tabular}{|c|c|c|c|c|}
\hline & Jacarezinho & Andira & Patos & Viçosa \\
\hline Londrina & $\star *$ & $\star \star$ & ns & $\star *$ \\
\hline Jacarezinho & - & $\star *$ & $\star \star$ & $\star \star \star$ \\
\hline Andira & . & - & $\star \star \star$ & $\star \star \star$ \\
\hline Patos & & & - & $\star \star \star$ \\
\hline
\end{tabular}


Tabela 5.2.a - Agrupamentos dos locais segundo a significância da in teração cultivar por local para o ano agrícola 1977/ 78.

\begin{tabular}{|c|c|c|c|c|c|c|}
\hline & $\begin{array}{c}\text { Capinō- } \\
\text { polis }\end{array}$ & Guaíra & Maduri & Londrina & Patos & Viçosa \\
\hline Campinas & ns & ns & $\star \star$ & ns & * & ns \\
\hline Capinopolis & - & 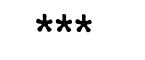 & ns & ns & ns & ns \\
\hline Guaíra. & & - & $\star \star$ & * & ns & ns \\
\hline Maduri & & & - & ns & $\star \star \star \star$ & $\star *$ \\
\hline Londrina & & & & - & $\star$ & $\star \star$ \\
\hline Patos & & & & & - & ns \\
\hline
\end{tabular}

Tabela 5.2.b - Agrupamentos dos locais segundo a significância da in teração cultivar, por local para o ano agrícola 1977/ 78.

\begin{tabular}{lcc}
\hline & Cravinhos & Pindorama \\
\hline Uberaba & $\star \star$ & ns \\
Cravinhos & - & $\star \star$ \\
\hline
\end{tabular}


Tabela 5.3.a - Agrupamentos dos locais segundo a significância da in teração cultivar por local para o ano agrícola 1978/ 79.

\begin{tabular}{lcccc}
\hline & Guaíra & Cravinhos & Pindorama & Andirá \\
\hline Uberaba & ns & $\star \star$ & ns & ns \\
Guaíra & - & ns & ns & $\star \star$ \\
Cravinhos & & - & ns & ns \\
Pindorama & & & - & ns \\
Andirá & & & & - \\
\hline
\end{tabular}

Tabela 5.3.b - Agrupamentos dos 1ocais segundo a significância da in - teração cultivar por local para o ano agrícola 1978/ 79 .

\begin{tabular}{lccc}
\hline & Capinópolis & Maduri & Sete Lagoas \\
\hline Campinas & $\star$ & ns & $\star$ \\
Capinōpolis & - & $\star \star$ & ns \\
Maduri & & - & $\star \star$ \\
\hline
\end{tabular}


Tabela 5.4.a - Agrupamentos dos locais segundo a significância da in teração cultivar por local para o ano agrícola 1979/ 80 .

\begin{tabular}{|c|c|c|c|c|c|c|}
\hline & Guaíra & Inhumas & $\begin{array}{c}\text { Cravi- } \\
\text { nhos }\end{array}$ & Manduri & $\begin{array}{l}\text { Jardinō- } \\
\text { polis }\end{array}$ & $\begin{array}{c}\text { Sete } \\
\text { Lagoas }\end{array}$ \\
\hline Itatiba & ns & * & ns & ns & ns & * \\
\hline Guaíra & - & ns & ns & ns & ns & ns \\
\hline Inhumas & & - & $\star * *$ & ns & $\star \star$ & $\star \star \star t$ \\
\hline Cravinhos & & & - & $\star *$ & $\star *$ & $\star \star$ \\
\hline Manduri & & & & - & $\star \star \star *$ & $\star \star$ \\
\hline Jardinōpolis & & & & & - & * \\
\hline
\end{tabular}

Tabela 5.4.b - Agrupamentos dos locais segundo a significância da in teração cultivar por local para o ano agrícola 1979/ 80 .

\begin{tabular}{lccccc}
\hline & Goiânia & Capinōpolis & Uberaba & Londrina & Viçosa \\
\hline Campinas & $\star \star \star$ & $\star \star \star$ & $\star \star \star$ & $\star \star$ & $\star \star$ \\
Goiânia & - & $\star \star$ & ns & ns & $\star$ \\
Capinōpolis & - & $\star \star \star$ & ns & $\star \star$ \\
Uberaba & & - & $\star$ & $\star$ \\
Londrina & & & & - & $\star \star$ \\
\hline
\end{tabular}


4.3 - Anālise da Variāncia Conjunta dos Dados de 36 Cultivares em Sete Locais, Considerando Modelo Aleatōrio

\subsection{1 - Conjuntos de locais para o ano agrícola 1976/77}

Para o ano agricola de $1976 / 77$, o conjunto de locais utilizando-se o critērio baseado nos valores da estatistica $\mathrm{F}$ para a interação ( $T x L)$ foi o seguinte:

CONJUnTO 5.1.a: Campinas, Guaira, Manduri, Pindorama, Jardinópolis, Sete Lagoas e Jaiba.

A anālise de variāncia conjunta efetuada conforme o esquema descrito na Tabela 2 do item 3.2.1, para esse conjunto, è apresentada na Tabela 6.1.a.

Tabela 6.1.a - Anālise da variāncia conjunta das sete localidades do conjunto 5.1.a do ano agricola 1976/77.

\begin{tabular}{lrrrr}
\hline Causas da Variação & G.L. & S.Q. & Q.M. & F \\
\hline Local (L) & 6 & 751 (L $543.260,70$ & & \\
Cultivar (T) & 35 & $21.719 .220,00$ & & \\
Interação (TxL) & 210 & $62.339 .920,30$ & $296.856,76$ & $1,32 *$ \\
\hline Res. Médio Comb. & 735 & & $224.309,15$ & \\
\hline Média = 5.411,00 kg & & & &
\end{tabular}


Verifica-se, pela Tabela 6.1.a, que a magnitude do $Q M(T x L)=296.856,76$ apresenta uma redução de $24,29 \%$ relativamente ao $\mathrm{QM}(\mathrm{TxL})=391.414,45$ da análise da variância conjunta da Tabela 3.1, que envolve os 18 locais do ano agrícola em questão.

Essa interação $Q M(T x L)$ do quadro 6.1.a quando relacionada com o QMR dos sete locais envolvidos dá origem a um valor $F=1,32$, inferior, portanto, ao do quadro 3.1 que $\bar{e} F=2,45$. Embo ra esse $F(1,32)$ continue significativo, a proporcionalidade existente entre o efeito da interação e a magnitude do $\mathrm{F}$ mostra redução no efeito da interaçâo, como se desejava.

CONJUNTO 5.1.b: Londrina, Jacarezinho, Andirā, Patos e Viçosa. Para esse conjunto, seguindo o mesmo processo de ana lise do conjunto anterior, foram encontrados os resultados da Tabe1a $6.1 . \mathrm{b}$.

Tabela 6.1.b - Anālise da variância conjunta das cinco localidades do conjunto 5.1.b do ano agrícola 1976/77.

\begin{tabular}{lrccc}
\hline Causas da Variação & G.L. & S.Q. & Q.M. & F \\
\hline Local (L) & 4 & $335.784 .752,20$ & & \\
Cultivar (T) & 35 & $31.076 .496,00$ & & \\
Thteração TxL & 140 & $51.855 .392,00$ & $370.395,65$ & $2,85 *$ \\
\hline Reș Mèdio Comb. & 525 & $\ldots$ & $129.751,30$ & \\
\hline
\end{tabular}

Média $=5.468,13 \mathrm{~kg}$

$C_{,} \forall,=11,13 \%$ 
Para este conjunto (6.1.b) houve uma redução no $\mathrm{QM}(\mathrm{TxL})=370.395,65$ de 5,37\% em relação ao $\mathrm{QM}(\mathrm{TxL})=391.414,45$ que se encontra na Tabela 3.1. Quanto ao valor de $F=2,85$ para a interação QM(TxL), houve un aumento em relação ao encontrado na Tabela 3.1 .

Este conjunto, portanto, não mostrou as vantagens en contradas no conjunto 5.1.a, que apresentou maior homogeneidade.

\subsection{2 - Conjuntos de locais para o ano agrícola 1977/78}

Um procedimento anālogo ao seguido para o ano agríco la $1976 / 77$ permitiu obter os seguintes conjuntos de locais.

CONJUNTO 5.2.a: Campinas, Capinōpolis, Guaíra, Manduri, Londri na, Patos e Viçosa;

CONJUNTO 5.2.b: Uberaba, Cravinhos e Pindorama.

As anālises de variância relativas aos referidos con juntos encontram-se nas Tabelas 7.2.a e 7.2.b.

Tabela 7.2.a - Anālise da variância conjunta das sete localidades do conjunto 5'.2.a do ano agrícola 1977/78.

\begin{tabular}{lrrrr}
\hline Causas da Variação & G.L. & S.Q. & Q.M. & F \\
\hline Local (L) & 6 & $1.214 .780 .893,00$ & \\
Cultivar (T) & 35 & $46.895 .900,00$ & & \\
Interação TxL & 210 & $69.753 .732,00$ & $332.160,62$ & $1,47 *$ \\
\hline Res. Médio Comb. & 735 & & $225.470,49$ & \\
\hline Média $=4.859,30 \mathrm{~kg}$ & & & & \\
C.V. $=11,86 \%$ & & & &
\end{tabular}


Tabela 7.2.b - Análise da variância conjunta das três localidades do conjunto 5.2.b do ano agrícola 1977/78.

\begin{tabular}{lrrrr}
\hline Causas da Variação & G.L. & S.Q. & Q.M. & F \\
\hline Local (L) & 2 & $324.078 .636,20$ & \\
Cultivar (T) & 35 & $50.353 .002,00$ & & \\
Interação TxL & 70 & $21.885 .218,00$ & $312.645,97$ & $1,69 *$ \\
\hline Res. Médio Comb. & 315 & & $184.910,20$ & \\
\hline
\end{tabular}

Média $=4.193,00 \mathrm{~kg}$

C.V. $=13,57 \%$

Em ambos os casos analisados verificam-se reduções nos quadrados médios das interações, que são de $46,22 \%$ e $49,38 \%$, res pectivamente.

A vantagem na formação dos conjuntos citados pode ser vista tambēm através do valor da estatística $F$ para o QM(TxL), que teve seu valor consideravelmente reduzido.

4.3.3 - Conjuntes de locais para o ano agrícola 1978/79

Seguindo os mesmos critērios dos ítens 4.3.1 e 4.3.2, foram obtidos dois conjuntos para o ano agrícola 1978/79, designados por 5.3.a e 5.3.b.

CONJUNTO 5.3.a: Uberaba, Guaíra, Cravinhos, Pindorama, Andirā. CONJUNTO 5.3.b: Campinas, Capinópolis, Manduri e Sete Lagoas. 
As Tábelas 8.3.a e 8.3.b apresentam os resultados das anālises da variância efetuadas para os conjuntos mencionados.

Tabela 8.3.a - Anālise da variância conjunta das cinco localidades do conjunto 5.3.a do ano agrícola 1978/79.

\begin{tabular}{lrrrr}
\hline Causas da Variação & G.L. & S.Q. & Q.M. & F \\
\hline Local (L) & 4 & $634.689 .640,50$ & \\
Cultivar (T) & 41 & $119.727 .328,00$ & & \\
Interação TxL & 164 & $82.771 .016,00$ & $504.701,31$ & 1,37 * \\
\hline Res. Médio Comb. & 615 & & $368.626,50$ & \\
\hline
\end{tabular}

Média $=7.172,70 \mathrm{~kg}$

C.V. $=9,90 \%$

Tabela 8.3.b - Anālise da variância conjunta das quatro localidades do conjunto 5.3.b do ano agrícola 1978/79.

\begin{tabular}{lrrrr}
\hline Causas da Variação & G.L. & S.Q. & Q.M. & F \\
\hline Local ... (L). & 3 & $207.986 .864,10$ & & \\
Cultivar (T) & 41 & $113.167 .444,00$ & & \\
Interação TxL & 123 & $51.826 .980,00$ & $421.357,56$ & $1,58 *$ \\
\hline Res. Médio Comb. & 492 & & $265.787,50$ & \\
\hline
\end{tabular}

Mẻdia $=7.072,60 \mathrm{~kg}$

C. v. $=9,17 \%$ 
A análise da variância considerando-se cinco localida des, encontra-se na Tabela 8.3.a, onde se verifica que o QM(TxL) = $=504.701,31$ apresenta uma diminuição de $13,24 \%$ em relação ao QM(TxL) $=581.781,30$ da Tabela 3.3, mostrando real vantagem na formação des te conjunto de locais.

Da mesma forma, verificamos, pela Tabela 8.3.b, que houve uma redução do $\mathrm{QM}(\mathrm{TxL})=421.357,56$ da ordem de $27,57 \%$ em relação ao $\mathrm{QM}(\mathrm{TxL})=581.781,30$ da Tabela 3.3.

Para ambas as Tabelas, a estatística F apresentou re dução em sua magnitude, que era de 2,01 na Tabela 3.3, para 1,37 na Tabela 8.3.a, e 1,58 na Tabela 8.3.b.

\subsection{4 - Conjunto de locais para o ano agrícola 1979/80}

Os conjuntos formados para o ano agrícola de 1979/80 foram os seguintes.

CONJUNTO 5.4.a: Itatiba, Guaíra, Inhumas, Cravinhos, Manduri, Jardinōpolis e Sete Lagoas.

CONJUNTO 5.4.b: Campinas, Goiânia, Capinōpolis, Uberaba, Londrina e Viçosa.

Para o conjunto 5.4.a obteve-se a Tabela 9.4.a da análise da variância. 
Tabela 9.4.a - Anālise da variância conjunta das sete localidades do conjunto 5.4.a do ano agrícola 1979/80.

\begin{tabular}{lrccc}
\hline Causas da Variação & G.L. & S.Q. & Q.M. & F \\
\hline Local (L) & 6 & $283.167 .096,20$ & & \\
Cultivar (T) & 41 & $241.342 .968,10$ & & \\
Interação TxL & 246 & $127.407 .488,00$ & $517.916,61$ & $1,56 *$ \\
\hline Res. Médio Comb. & 861 & & $330.766,70$ & \\
\hline
\end{tabular}

Média $=7.511,20 \mathrm{~kg}$

C.v. $=9,58 \%$

Verifica-se pela Tabela 9.4.a que o $Q M(T x L)=517.916,61$

$\overline{\mathrm{e}}$ inferior ao $\mathrm{QM}(\mathrm{TxL})=699.780,78$ da Tabela 3.4, apresentando uma redução de $25,99 \%$. O valor da estatística $\mathrm{F}$ também apresenta uma re dução de 2,36 da Tabela 3.4 para 1,56 da Tabela 9.4.a.

Diante do exposto, parece não haver dúvidas quanto a vantagem na formação deste conjunto.

Com relação ao conjunto $5.4 . b$, sua anảlise da variân cia encontra-se na Tabela 9.4.b. 
Tabela 9.4.b - Anālise da variância conjunta das seis localidades do conjunto 5.4.b do ano agrícola $1979 / 80$.

\begin{tabular}{lrccc}
\hline Causas da Variação & G.L. & S.Q. & Q.M. & F \\
\hline Local (L) & 5 & $534.879 .560,30$ & & \\
Cultivar (T) & 41 & $260.385 .104,10$ & & \\
Interação TxL & 205 & $134.144 .896,00$ & $654.365,34$ & $1,91^{*}$ \\
\hline Res. Médio Comb. & 738 & & $341.219,50$ & \\
\hline
\end{tabular}

Média $=6.395,30 \mathrm{~kg}$

c.v. $=12,64 \%$

Comparando-se o QM(TxL) da Tabela 9.4.b com o QM(TxL) da Tabela 3.4, verifica-se uma redução de 6,49\%. Quanto ao valor da estatística $F$, a redução é de 2,36 da Tabela 3.4 para 1,91 da Tabe1a 9.4.b: Constata-se, assim, alguma vantagem na formação deste con junto.

4.4 - Estimação dos Componentes de Variância $\left(\hat{\sigma}_{t \ell}^{2}\right)$ da Interação Cultivar por Local, para o Período de 1976 a 1980, Conside rando os Grupos Formados Dentro de Cada Ano

A fim de avaliar a redução da magnitude dos componen tes da variância $\left(\hat{\sigma}_{t \ell}^{2}\right)$ da interação cultivar por local, foram feitas estimativas desses componentes por ponto e por intervalo de con fiança, seguindo a metodologia do ítem 3.2.3.

Para uma apreciação global, apresentam-se os resultạ dos dessas estimativas na Tabela 10. 


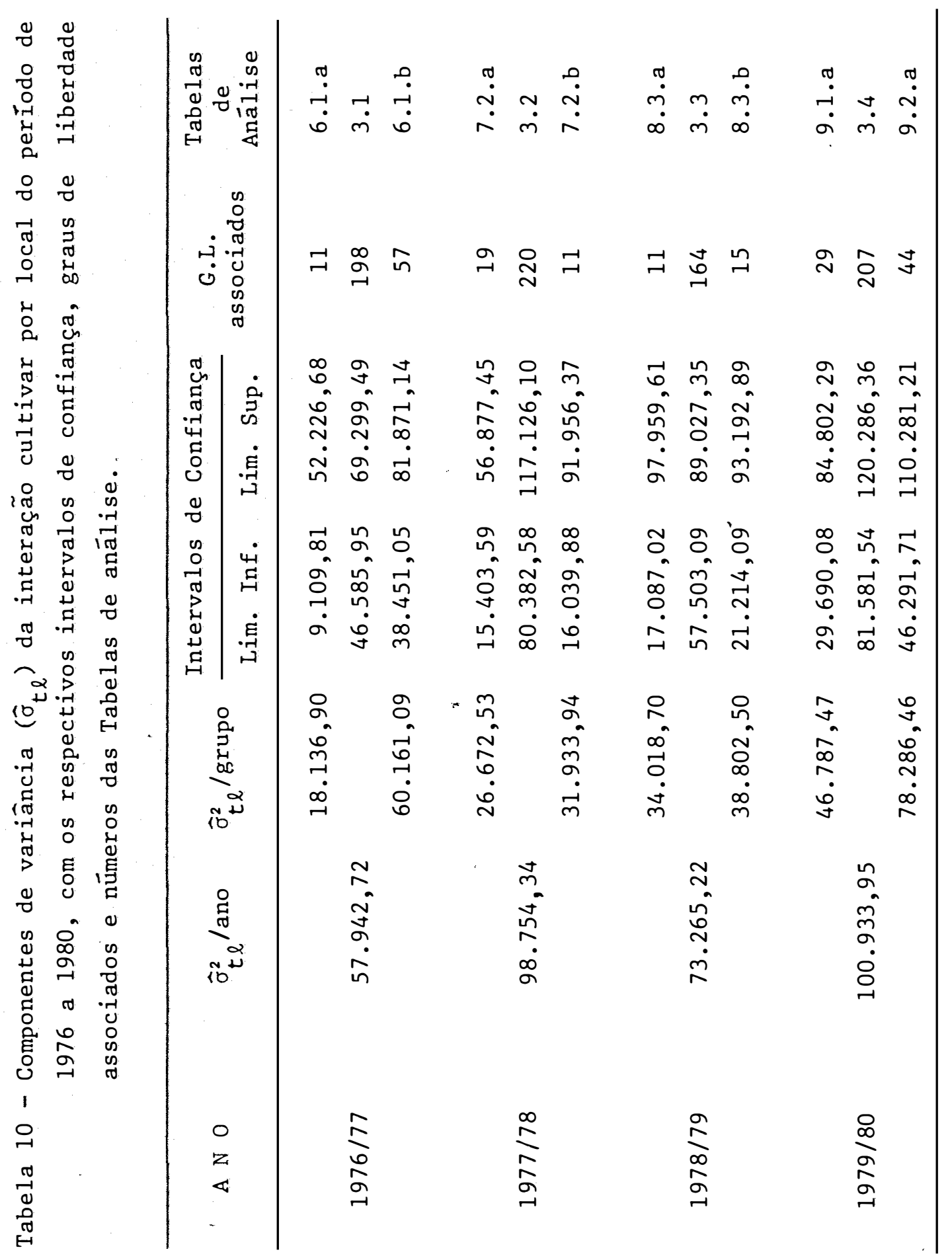


Como se pode verificar pela inspeção da Tabela 10, houve reduções apreciāveis nas magnitudes dos componentes da variân cia da interação, tanto para os conjuntos de locais "a" como para os "b", em relação aos componentes de variância da interação cul tivar por local dos anos agrícolas 1977/78, 1978/79 e 1979/80.

Com relação ao ano agrícola $1976 / 77$ houve considerāvel redução na componente $\ddot{\partial}_{t \ell}^{2}$ somente para o conjunto de locais 5.1.a. Deve ser notado que a comparação entre QM(TxL) para o conjun to de locais $5.1 . \mathrm{b}$ mostrou uma redução de apenas $5,37 \%$ em relação ao $\mathrm{QM}(\mathrm{TxL})$ do ano de $1976 / 77$, enquanto que o componente da interação para esse conjunto foi até um pouco maior do que a verificada pa ra o mesmo ano. Isto nos leva a considerar o conjunto $5.1 . b$ como sen do não satisfatōrio em termos do que se pretendia com a sua formação. Uma consu1ta à Tabela $6.1 . \mathrm{b}$ pode trazer algum esclarecimento quanto à crítica feita ao conjunto de locais.

Pode-se verificar que os limites inferiores para os intervalos de confiança dos conjuntos "a"s são sempre menores que os limites inferiores dos intervalos de confiança dos"b"s. Este fä to pode ser explicado pelo maior rigor na formação dos primeiros, com base na significância dos valores da estatística F, como se pode verificar consultando, em sequência, as Tabelas 5.1.a até 5.4.b. Verificando-se os limites superiores dos intervalos de confiança dos conjuntos de locais a(s) nota-se que são menores do que os limites superiores dos $b(s)$, com uma única exceção, verifica 
38.

da no ano agrícola 1978/79.

De modo geral, as observações feitas para os limites superiores dos intervalos de confiança reforçam as considerações apresentadas quanto aos limites inferiores, desde que se considere co mo praticamente desprezível a diferença encontrada entre os limites superiores dos intervalos de confiança dos conjuntos "a" e "b" para o ano agrícola 1978/79.

Ainda com relação à Tabela 10 , pode-se verificar que as amplitudes dos intervalos de confiança para os conjuntos de 1ocais "a" e também para os conjuntos de locais "b" são sempre maiores do que as amplitudes dos intervalos de confiança para os anos agrícolas correspondentes. Tal fato pode, possivelmente, ser explicado pelo número mais elevado de graus de liberdade para cada ano do período, quando comparados com os números de graus de liberdade dos conjuntos considerados.

Finalmente, a Tabela 10 permite constatar que 0 ano agrícola de 1976/77 foi o que apresentou o menor componente da inte ração $\widehat{\sigma}_{t \ell}^{2}$, seguido do ano de 1978/79, que, por sua vez, foi seguido tos anos de 1977/78 e 1979/80 de valores semelhantes. 
39.

5. CONCLUSOES

0 presente estudo permite chegar às seguintes conclusões :

5.1 - Os dados de produção de milho, representados pelas médias de quatro repetições por local, referentes ao periodo agri cola 1976/77 a 1979/89, para localidades da região Centro do Brasil (segundo boletins da EMBRAPA), apresentaram algu mas limitações, pelo fato de que as cultivares e as locali dades variaram conforme o ano.

5.2 - 0 método de agrupamento, baseado em valores da estatistica F correspondente à interação QM (TxL), permitiu a formação de trēs subconjuntos de locais ( $a, b$ e c), em ordem decres cente quanto à homogeneidade. 
5.3 - Os subconjuntos "a" e "b", analisados segundo a Tabela 2 do item 3.2.1, constituiram, separadamente, grupos de 1ocais ecologicamente semelhantes.

5.4 - Os subconjuntos tipo "c", aos quais corresponderam os mais elevados valores de. F (significativos), empregando-se a me todologia descrita no item 3.2.2, foram descartados em vir tude de suas heterogeneidades.

5.5 - 0 método utilizado no presente trabalho revelou-se um instrumento ütil para a obtenção de grupos homogēneos com sen siveis reduções nos QM ( $T x L)$, e inclusive nos coeficientes de variação.

5.6 - A metodologia deste trabalho é recomendável para novas pes quisas, sendo tanto mais adequada quanto menores forem as limitações apresentadas pelos dados e maior o número de lo cais envolvidos no estudo. 
41.

6. BIBLIOGRAFIA

ABOU-EL-FITTOUH, H.; J.O. RAWLINGS e P.A. MILLER, 1969. Classifica tions of environments to control genotypes by environment interactions with application to cotton. Crop Science. Madison, 9: 135-140.

ALLARD, R.W. e A.O. BRADSHAW, 1964. Implications of genotype environment interactions in applied plant breeding. Crop Science. Madison, 4: 503-507.

CAMPBELL,L.G. e H.N. LAFEVER, 1977. Cultivar x environment interaction of soft red winter yield test. Crop Science. Madison, 17: 607-608.

COCHRAN, W.G. e G.M. COX, 1957. Experimental Designs. 2. ed. Nova York. $611 \mathrm{pp}$.

CORDEIRO, C.M.T., 1978. Estudo do zoneamento da região Centro-Su1 do Brasil para a cultura do Milho. Brasilia, UNB, 104 pp. (Dissertação de Mestrado). 
EBERHART, S.A. e W.A. RUSSEL, 1966. Stability parameters for varieties. Crop Science. Madison, 6: 36-40.

FREEMAN, G.H., 1973. Statistical methods for the analysis of genotype-environment interactions. Heredity. Londres, 31: 339-354.

HORNER, T.W. e K.J. FREY, 1957. Methods for determining natural areas for oat varietal recomendations. Agronomy Journal. Wisconsin, 49: 313-315.

IGNAZAK, J.C. e J.G. SILVA, 1978. Análise conjunta de grupo de ex perimentos com alguns locais e tratamentos não comuns. Pesq. Agropec. Bras. Brasilia, 13(3): 59-66.

JOWETT, D., 1972. Yield stability parameters for sorghum in East Africa. Crop Science. Madison, 12: 314-317.

KEMPTHORNE, 0., 1975. The Design and Analysis of Experiments. Nova York, Robert E. Kreeger Publishing. 641 pp.

LIANG, G.H.L.; E.G. HEINE e T.L. WALTER, 1966. Estimates of variety-environment interactions in yield test and their significance in breeding programs. Crop Science. Madison, 6: 135-139.

MCCAIN, F.S. e E.F. SCHULTZ Jr., 1959. A method for determining areas for corn varietal recommendations. Agronomy Journal. Madison, 51: 476-478.

MOREIRA, J.C.S.; E.A. OSÓRIO; M.C. MEDEIROS; F.A. LANGER; V.I. LINHARES; E.P. GOMES; C.N.A. SOUZA E G.C. COPPOLA, 1971. Cultura do trigo. Instituto de Pesquisas Agropecuārias do Sul. Pelotas, Circ. 48: 19-29. 
OSORIO, E.A.; J.C.S. MOREIRA; E.C. da SILVA, 1974. Estudos de adap tação de cultivares de trigo no Rio Grande do Sul. I. Adaptação regional das cultivares precoces. Pesq. Agropec. Bras. Rio de Janeiro, Sērie Agron. 9: 151-154.

PARODA, R.S. e J.D. HAYES, 1971. An investigation of genotype-environment interactions for rate of ear emergence in Spring Barley. Heredity. Londres, 26: 157-175.

PIMENTEL GOMES, F., 1976. Curso de Estatística Experimental. 6 a ed. Piracicaba, Livraria Nobel. 430 pp.

ROBERTSON, A., 1959. The sampling variance of the genetic correlatio coeficient. Biometrics. Raleigh, 15: 469-485.

ROSITO, C., 1974. Interação genótipo por locais en trigo no Rio Grande do Sul. Piracicaba, ESALQ/USP. 61 pp. (Dissertação de Mestrado).

RUSCHEL, R., 1968. Interação Genótipo x Loccalidades na Região Centro-Sul do Brasil em Milho (Zea mays L.). Piracicaba, ESALQ/USP. 60 pp. (Dissertação de Mestrado).

SATTERTHWAITE, F.E., 1946. An approximate contribution to estimate of variance components. Brom Bul1. 2: 110-114.

SCHLEHUBER, A.M.; J.C.S. MOREIRA e M.C. MEDEIROS, 1970. Estudo de correlações simples entre ensaios de variedades de trigo realizados no Rio Grande do Sul. Pesq. Agropec. Bras. Rio de Janeiro, Série Agron. 5: 235-241. 
SHUKLA, G.K., 1972. Some statistical aspects of partitioning genotype-environmental components of variability. Heredity. Londres, 28: $237-245$.

SILVA, C.S., 1981. Classificações ambientais para controlar a inte ração genótipo $\mathrm{x}$ ambiente com aplicação à cultura do trigo no Rio Grande do Sul. Piracicaba, ESALQ/USP. 75 pp. (Tese de Doutoramento).

SILVA, J. e R. MAGNAVACA, 1970. Determinação de āreas para a indicação de cultivares de milho. In: Anais da VIII Reunião Brasileira de Milho. Porto Alegre, p. 30-32.

SILVA, W.J.; L.T. MIRANDA e G.P. VIEGAS, 1963. Estimativa do progresso genōtipo mẻdio em ensaios de cultivares de milho. Bragantia. Campinas, 22: 247-258.

SILVEIRA, E.P.,-1980. Interação genótipos por locais em arroz de sequeiro no Estado de São Paulo. Piracicaba, ESALQ/USP. 97 pp. (Dissertação de Mestrado).

SNEDECOR, R.G.W. e W.G. COCHRAN, 1967. Statistical Methods. 6. ed. The Iowa State University Press, Ames, Iowa. 593 pp.

STEEL, R.G.D. e J.H. TORRIE, 1960. Principles and Procedures of Statistics. Nova York, McGraw-Hi11 Book Company, Inc. 481 pp.

TAI, G.C.C., 1971. Genotype stability analysis and its application to potato regional trials. Crop Science. Madison, 11: 184-190.

TAI, G.C.C., 1979. Analysis of genotype-environment interactions of potato yield. Crop Science. Madison, 19: 434-438. 
45.

7. APENDICE 


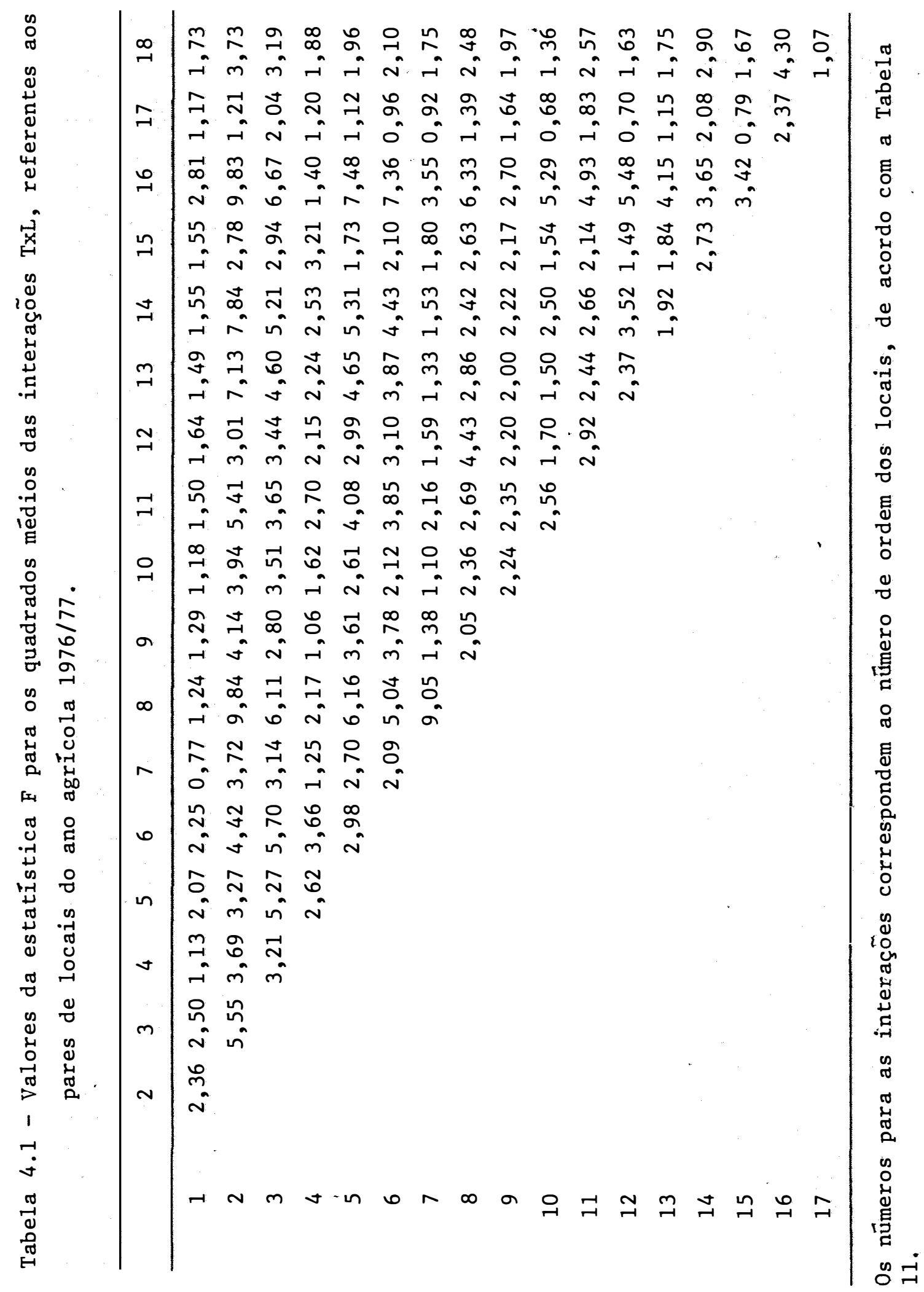


47.

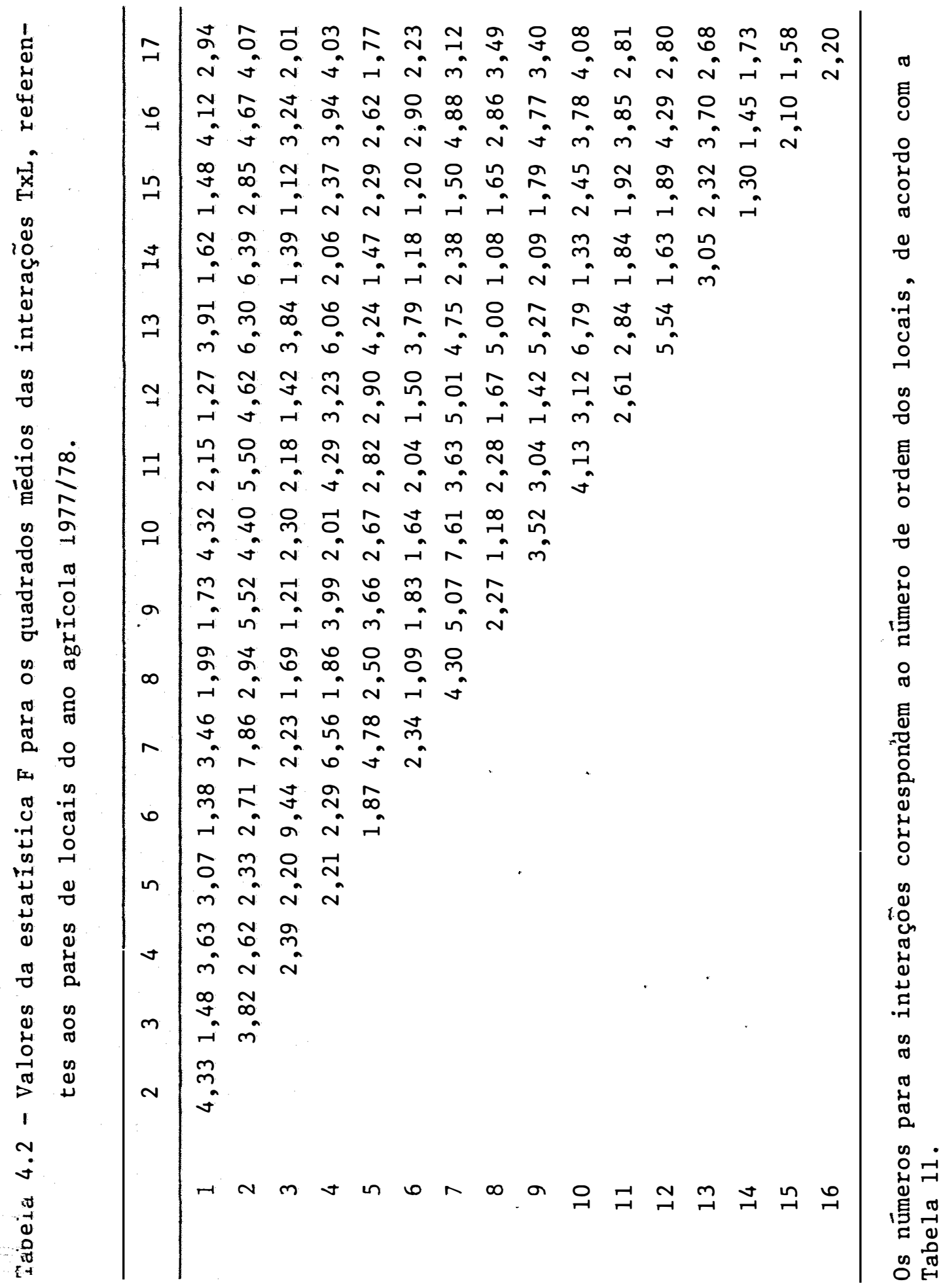




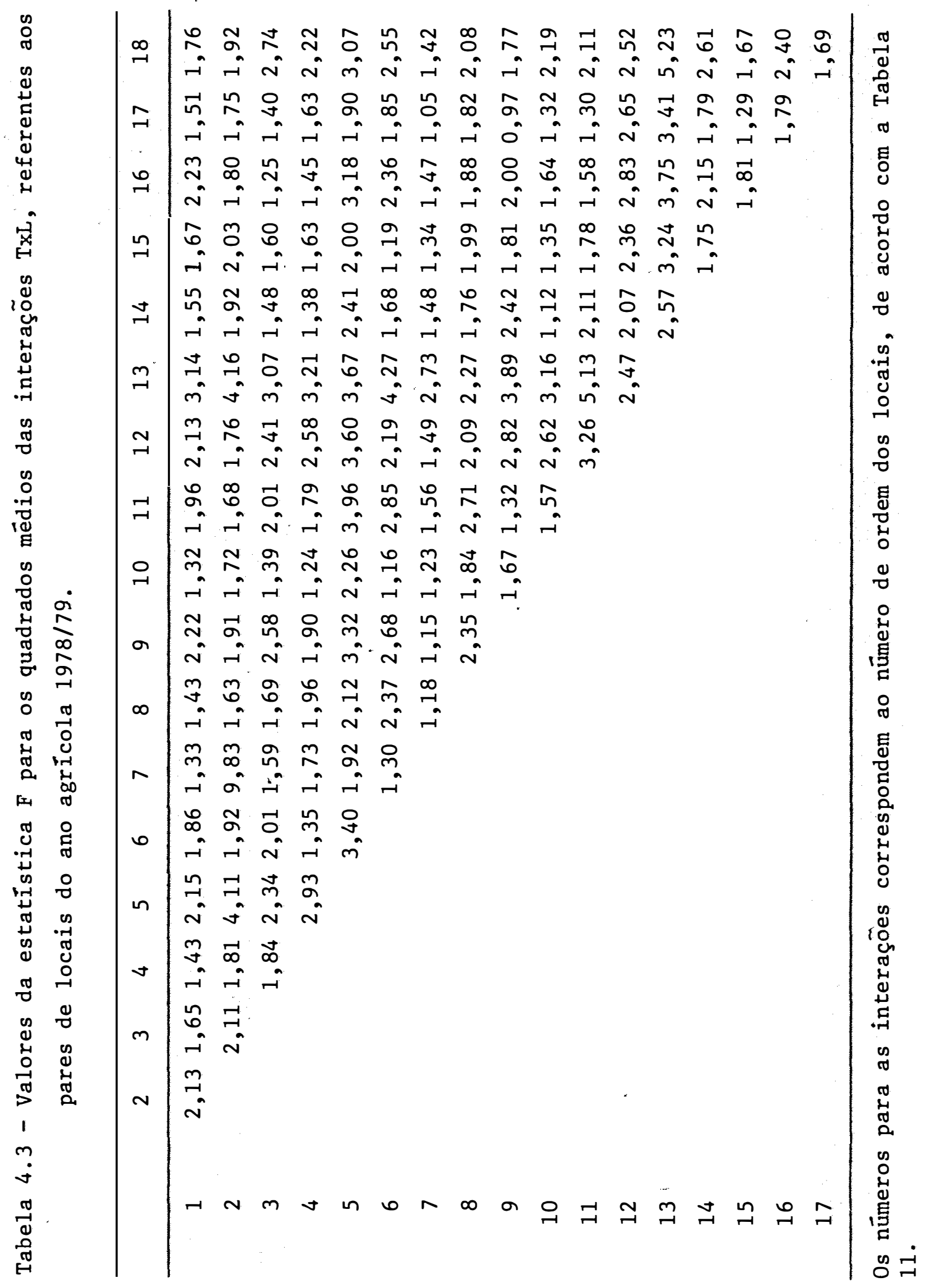




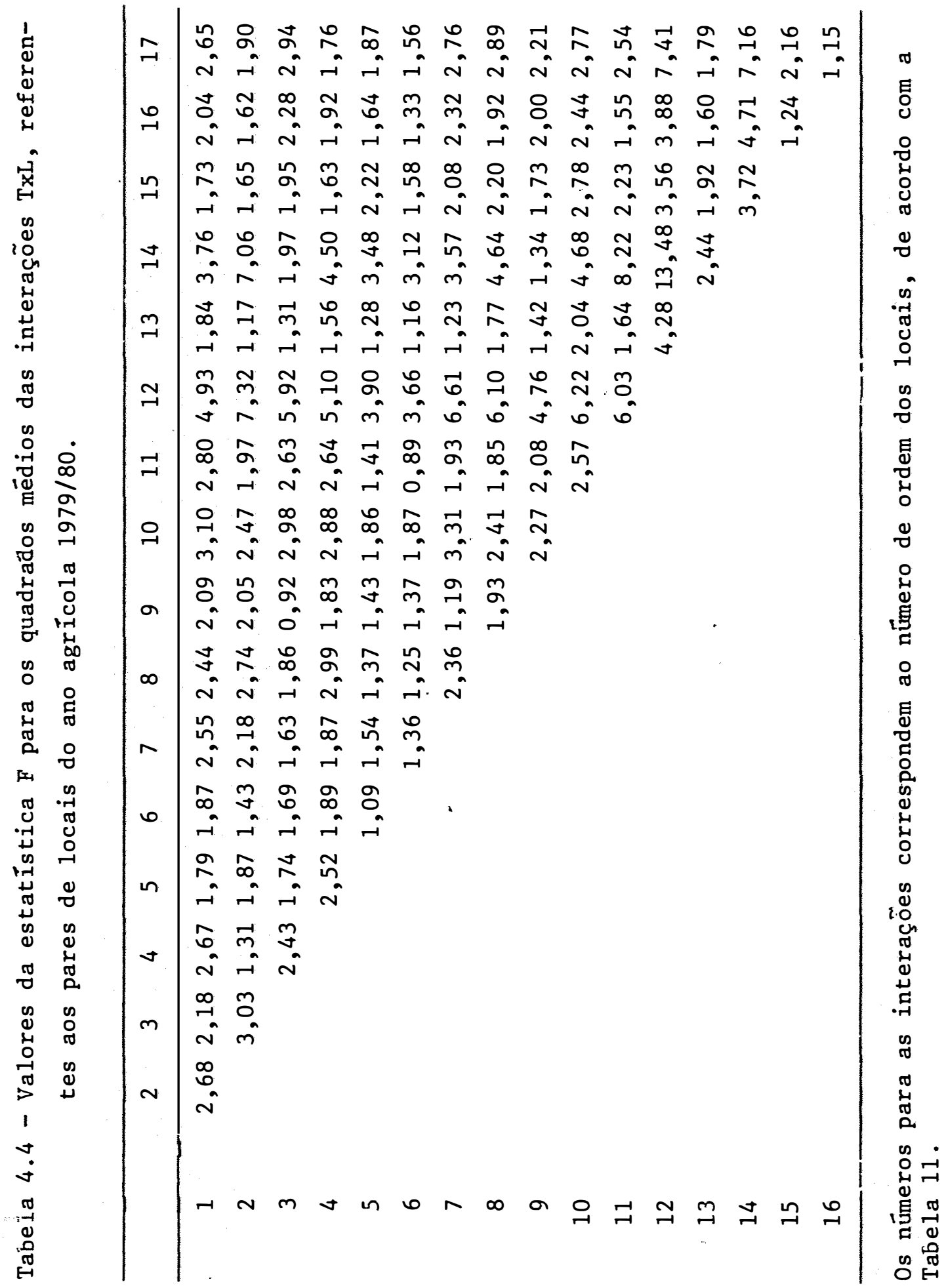


Tabela 11 - Quadrados médios residuais para os locais segundo o ano agrícola.

\begin{tabular}{|c|c|c|c|c|c|}
\hline \multicolumn{3}{|c|}{ ANO $1(1976 / 77)$} & \multicolumn{3}{|c|}{ ANO $2(1977 / 78)$} \\
\hline NO & Locais & QMR & No & Locais & QMR \\
\hline 1 & Campinas & $1.279 .193,7992$ & 1 & Campinas & $401.011,642$ \\
\hline 2 & Goiania & $279.981,2026$ & 2 & Goiania & $579.545,259$ \\
\hline 3 & Uberaba & $483.695,7687$ & 3 & Capinōpolis & $667.242,289$ \\
\hline 4 & Guaíra & $657.653,6887$ & 4 & Uberaba & $823.145,930$ \\
\hline 5 & Inhumas & $313.475,1324$ & 5 & Itatiba & $1.246 .308,770$ \\
\hline 6 & Cravinhos & $249.407,6053$ & 6 & Guaíra & $734.386,612$ \\
\hline 7 & Manduri & $621.332,2295$ & 7 & Inhumas & $268.417,248$ \\
\hline 8 & Rib. Preto & $117.274,0572$ & 8 & Cravinhos & $821.352,682$ \\
\hline 9 & Pindorama & $1.046 .303,9521$ & 9 & Manduri & $407.310,575$ \\
\hline 10 & Jardinōpolis & $367.519,4463$ & 10 & Pindorama & $574.423,930$ \\
\hline 11 & Jaboticabal & $994.821,1226$ & 11 & Jaboticabal & $713.548,162$ \\
\hline 12 & Londrina & $374.335,4489$ & 12 & Londrina & $399.206,622$ \\
\hline 13 & Jacarezinho & $271.546,2522$ & 13 & Andirā & $1.057 .507,836$ \\
\hline 14 & Andirā & $392.066,9533$ & 14 & Patos & $1.744 .408,784$ \\
\hline 15 & Patos & $1.202 .580,6882$ & 15 & Viçosa & $1.659 .607,644$ \\
\hline 16 & Viçosa & $354.497,3495$ & 16 & Sete Lagoas & $1.481 .438,056$ \\
\hline 17 & Sete Lagoas & $1.550 .456,1455$ & 17 & Jaîba & $1.264 .130,016$ \\
\hline \multirow[t]{2}{*}{18} & Jaíba & $678.197,5433$ & & & \\
\hline & TOTAL & $11.494 .338,8855$ & & TOTAL & $15.140 .9 .92,057$ \\
\hline
\end{tabular}


Tabela 11 - continuação.

\begin{tabular}{|c|c|c|c|c|c|}
\hline \multicolumn{3}{|c|}{ ANO $3(1978 / 79)$} & \multicolumn{3}{|c|}{ ANO $4(1979 / 80)$} \\
\hline NQ & Locais & QMR & No & Locais & QMR \\
\hline 1 & Campinas & $1.075 .096,079$ & 1 & Campinas & $1.462,456,072$ \\
\hline 2 & Goiania & $784.765,377$ & 2 & Goiania & $398.527,190$ \\
\hline 3 & Capinōpolis & $740.067,226$ & 3 & Capinōpolis & $1.307 .519,067$ \\
\hline 4 & Uberaba & $1.650 .640,377$ & 4 & Uberaba & $1.317 .679,002$ \\
\hline 5 & Itatiba & $932.692,378$ & 5 & Itatiba & $1.249 .230,936$ \\
\hline 6 & Guaîra & $1.385 .082,312$ & 6 & Guaîra & $2.374 .092,374$ \\
\hline 7 & Cravinhos & $1.454 .600,744$ & 7 & Inhumas & $714.191,982$ \\
\hline 8 & Manduri & $923.142,789$ & 8 & Cravinhos & $694.533,892$ \\
\hline 9 & Rib. Preto & $746.643,924$ & 9 & Manduri & $1.741 .003,720$ \\
\hline 10 & Pindorama & $1.562 .930,030$ & 10 & Rib. Preto & $832.523,943$ \\
\hline 11 & Jard inōpolis & $404.280,806$ & 11 & Jardinópolis & $505.741,227$ \\
\hline 12 & Londrina & $1.069 .301,799$ & 12 & Jaboticabal & $538.382,606$ \\
\hline 13 & Jacarezinho & $391.394,128$ & 13 & Londrina & $1.510 .351,102$ \\
\hline 14 & Andira & $1.319 .278,284$ & 14 & Jacarezinho & $451.790,865$ \\
\hline 15 & Patos & $3.306 .368,356$ & 15 & Viçosa & $1.592 .737,489$ \\
\hline 16 & Viçosa & $843.483,541$ & 16 & Sete Lagoas & $2.082 .674,129$ \\
\hline 17 & Sete Lagoas & $1.514 .294,403$ & 17 & Jaíba & $847.622,314$ \\
\hline \multirow[t]{2}{*}{18} & Jaîba & $683.809,586$ & & & \\
\hline & TOTAL & $20.787 .872,139$ & & TOTAL & $20.131 .057,910$ \\
\hline
\end{tabular}

